\title{
Never Smoker
}

National Cancer Institute

\section{Source}

National Cancer Institute. Never Smoker. NCI Thesaurus. Code C65108.

A person who was not smoking at the time of the interview and has smoked less than 100 cigarettes in their life. 